\title{
Integration of a barley (Hordeum vulgare) molecular linkage map with the position of genetic loci hosting 29 developmental mutants
}

\author{
C Pozzi ${ }^{1}$, D di Pietro, G Halas, C Roig and F Salamini \\ Max-Planck-Institut für Züchtungsforschung, Carl-von-Linné -Weg, 1050829 Cologne, Germany
}

\begin{abstract}
The first step in positional gene cloning is the integration into available molecular maps of genetic loci for which mutant alleles exist. We report the placement of 29 barley developmental mutants on a restriction fragment length polymorphism-amplified fragment length polymorphism (RFLP-AFLP) map. The mapping procedure used homozygous mutant $F_{2}$ plants in an iterative process: once a mutant linked AFLP was found, primer combinations were successively selected to generate AFLP fragments more tightly linked to the mutant locus. The mutants considered were adp, als, aur-a1, aur-a2, br1, br2, bra-d7, cul3, cul5, cul15, cul16, den6, den8, dub1,
\end{abstract}

Keywords: linkage map; mutant mapping; AFLP

\section{Introduction}

Positional or map-based cloning techniques are widely used to identify genes defined by the existence of mutant alleles. In Arabidopsis, the information generated by the Genome Initiative has demonstrated the value of this approach to discover new gene functions (Lukowitz et al, 2000). In crop species, progress in the enrichment of molecular maps, as well as the availability of PCR-based markers and extensive collections of ESTs that facilitate SNP scanning, also favor the adoption of the positional cloning approach (Richmond and Somerville, 2000). Barley has a genome size of $5 \times 10^{9} \mathrm{bp}$ but, in spite of this size, positional cloning is feasible (Büschges et al, 1997; Lahaye et al, 1998; Schwarz et al, 1999). The first step in positional cloning is the localization, on the available molecular map, of the genetic loci defined by mutant alleles. We have developed a procedure for mapping barley mutants and DNA probes based on amplified fragment length polymorphism (AFLP), in combination with restriction fragment length polymorphism (RFLP) (Castiglioni et al, 1998). The strategy makes use of the Proctor $\times$ Nudinka (RFLP) map assembled by Heun et al (1991) and has proved to be reliable and efficient (Castiglioni et al, 1998; Pozzi et al, 2000; Schmitz et al, 2000; Müller et al, 2001). The positioning of mutant loci and expressed genes on the same linkage map allows the integration of map-based

Correspondence: F Salamini, Max-Planck-Institut für Züchtungsforschung, Carl-von-Linné-Weg, 10, 50829 Cologne, Germany. E-mail: salamini@mpiz-koeln.mpg.de

${ }^{1}$ Current address: Fondazione Parco Tecnologico Padano-CERSA, c/o DiProVe, University of Milano, 20133 Milano, Italy.

Received 18 October 2002; accepted 17 January 2003 hex-v3, hex-v4, int-c5, K, li, lig-a2, Ik2, Ik5, sld1, sld4, tr, trd, unc, uc2 and $u z$. The 29 mutant loci were linked to the closest molecular markers by distances ranging from 0 to $23 \mathrm{cM}$, with an average value of $3.8 \mathrm{cM}$ away. Since the efficiency of the mapping procedure is a function of the density of molecular markers, the RFLP-AFLP map of Castiglioni et al was further integrated with new AFLPs using 87 doubled haploid lines derived from the barley cross Igri $\times$ Danilo. A total of 819 mapped AFLP marker loci are now available in the combined map.

Heredity (2003) 90, 390-396. doi:10.1038/sj.hdy.6800259 cloning procedures with the choice of candidate genes. This approach has been successfully applied to the mapping of quantitative trait loci (QTLs) for disease resistance in Capsicum and in wheat (Faris et al, 1999), while in maize a candidate gene involved in flavone synthesis could be associated with resistance to corn earworm (Byrne et al, 1996). Further examples of the candidate gene approach for the cloning of monogenic traits in plants are reported in Molinero-Rosales et al (1999) and Müller et al (1995).

In this paper, we report on the enrichment of a barley molecular map by the addition of 368 AFLP loci and on the integration into this map of 29 genetic loci for which developmental mutants are described.

The mutations investigated in this paper can be described in the light of an interpretation of the morphology of the barley plant as a succession of growth units (phytomers; Bossinger et al, 1992). For the 29 mutants considered, growth units of a specific region of the plant, which assume characteristics proper to phytomers of other regions, are evident for uniculm, third outer glume, densinodosum, intermedium, branched and awned palea. Mutants characterized by the presence of modified organs on the unit of growth are liguleless, bracteatum, triple awned lemma and awned palea. Mutants with additional phytomeres are represented by densinodosum and branched.

\section{Materials and methods}

Plant material

A total of 87 doubled haploid barley lines (DH lines) were used to map 368 new AFLPs, which supplement 
the 511 already mapped by Castiglioni et al (1998). The 87 lines originated from a cross between the lines Igri and Danilo (courtesy of A Jahoor, Technische Universität München, Germany). Developmental mutants were from the collection maintained at the Max-Planck-Institut für Züchtungsforschung (MPIZ), Cologne, Germany. This includes mutant stocks obtained from the Barley Genetic Stock Center (BGS), Fort Collins, Colorado (at present Aberdeen, Idaho); the Istituto per la Cerealicoltura (FIOR), Fiorenzuola, Italy; and from Udda Lundqvist (UD), Svalöf Collection, Svalöv, Sweden. The origins of mutants are listed in Castiglioni et al (1998). Mapping populations of the mutants listed in Table 1 were grown in the field and phenotypes reclassified in greenhouse tests. Wild-type (WT) and mutant (M) plants were selected and stored as $\mathrm{F}_{3}$-seed families. Data concerning the sizes of the mapping populations are reported in Table 1. Current mutant symbols for the loci described are reported in column 3 of Table 1 according to the recommendations of Lundqvist et al (1997), Franckowiak (1997), Franckowiak et al (1997) and Franckowiak and Lundqvist (2002). In the following, the term 'revised nomenclature' refers to the gene symbols given in the four papers cited above. In Table 1, the symbols used by Gustafsson et al (1969) are also reported, where applicable.

\section{DNA techniques}

Seedlings were grown in the greenhouse and harvested at the four-leaf stage for DNA extraction. DNA was extracted using the QIAGEN (Hilden, Germany) kit adapted to 96-well microtiter plates. The original AFLP procedure described by Zabeau and Vos (1993) was carried out with the minor modifications specified by Castiglioni et al (1998).

\section{Construction of the molecular linkage map using $\mathrm{DH}$ lines of Igri $\times$ Danilo}

The mapping data for the Proctor $\times$ Nudinka population were integrated with a new set of AFLP bands mapped in an Igri $\times$ Danilo cross. EcoRI and MseI AFLP primers were combined in the same 72 primer combinations used to develop the Proctor $\times$ Nudinka AFLP-RFLP map (Castiglioni et al, 1998). Each AFLP fragment was identified by the number of its primer combination and by an additional digit that refers to the figure stored as 'Visual catalogue of AFLP bands polymorphic between the barley lines Igri and Danilo', at the web site http:// www.diprove.unimi.it/. A list of the AFLP bands mapped on the Igri $\times$ Danilo molecular linkage map is given at the same web site. In the $87 \mathrm{DH}$ lines, polymorphic bands were scored as 0 or 1 for the absence or presence, respectively, and the data were tested for conformity to a $1: 1$ segregation ratio using a $\chi^{2}$ test $(P=0.05)$. Only bands whose segregation ratios did not deviate significantly from 1:1 were analyzed using the MAPMAKER program (Lander et al, 1987; DOS version 3.0). Recombination data were at first analyzed at a LOD value of 10.0, allowing the definition of 28 preliminary linkage groups. Of those groups, 11 were not positioned into the Nudinka $\times$ Proctor linkage groups since no bridge bands were shared by the Igri $\times$ Danilo and Nudinka $\times$ Proctor populations. On the remaining 17 preliminary linkage groups, a three-point analysis was carried out and the
ORDER routine of MAPMAKER was used to find the most probable order of their markers. An additional analysis at LOD 3.0 was performed on each group to confirm marker order and allow the integration of previously unmapped markers into preliminary linkage groups. Finally, the ORDER procedure was used to allow placement of markers previously not considered in the analysis and the TRY command allowed the placing of makers discarded by three-point analysis. Polymorphisms represented by segregating AFLP bands were assigned to chromosomes and chromosomal subgroups based on bridge AFLP loci that segregated both in the Igri $\times$ Danilo and Proctor $\times$ Nudinka populations. Identity of AFLP bands produced in the two populations by the same primer combination was assumed based on their electrophoretic mobility and relative intensity in gels (see also the Results and discussion).

\section{Integration of mutant loci into the molecular map} Linkage between mutants and markers was established based on DNA data from $\mathrm{F}_{3}$-seed families representing homozygous recessive $\mathrm{F}_{2}$ plants, as explained in Pozzi et al (2000). The size of the mapping populations is reported in Table 1, together with the number of mapping populations produced. When linkage between an AFLP band and a given mutant phenotype was established, the map position of the polymorphism was assigned based on the map of Castiglioni et al (1998), supplemented by the new Igri $\times$ Danilo data. Segregation data were analyzed with the MAPMAKER program with LOD score value 3.0 and a maximum distance of $50 \mathrm{cM}$. The mutant locus was represented by a virtual marker in complete linkage to the mutant phenotype in $\mathrm{F}_{2}$ plants. Coupling configurations - the presence of the AFLP band in the WT - were privileged because they allow the unambiguous classification of recombinants and, thus, a ready detection of putative cases of linkage. In case of the absence of recombination between a mutant and a specific AFLP loci, and in order to verify the actual existence in the $F_{2}$ population of the concerned AFLP polymorphism, five to $10 \mathrm{WT} \mathrm{F}_{2}$ plants were also analyzed.

\section{Results and discussion}

\section{The Igri $\times$ Danilo map}

The $87 \mathrm{DH}$ lines derived from the Igri $\times$ Danilo cross were analyzed with 72 AFLP primer combinations. Of 7668 readable bands (106.5 per primer combination), 520 were polymorphic and segregated in a ratio not significantly different from 1:1. Each primer combination yielded, on average, 6.9 polymorphic AFLP bands. In total, 72 AFLP markers were selected as bridges because they represented bands that migrated at identical positions on AFLP gels in both the Igri $\times$ Danilo and Proctor $\times$ Nudinka populations. Bridge bands were identified for 17 out of the 28 preliminary linkage groups and used to assign them to the seven linkage groups of the Proctor $\times$ Nudinka population (Heun et al, 1991). The final Igri $\times$ Danilo map included 368 AFLP markers out of the 520 newly detected. The reduction was a consequence of the presence of markers (1) placed on the 11 preliminary linkage groups that could not be assigned to a precise chromosomal location and (2) 
Table 1 Positions of 29 developmental mutant loci in the Proctor $\times$ Nudinka AFLP map (Linkage and linkage subgroups are assigned to each mutant locus.)

Mutant

Population size ${ }^{i}$

Symbol and name ${ }^{a}$

Mutant source

Cross

\begin{tabular}{|c|c|c|c|c|c|c|c|c|c|c|c|c|}
\hline & $\begin{array}{l}\text { Gustafsson et al } \\
\text { (1969) }\end{array}$ & $\begin{array}{l}\text { Recommended } \\
\text { nomenclature }\end{array}$ & & Map position ${ }^{c}$ & $N$ & $P$ & Closest markere & $\begin{array}{l}\text { Distancef } \\
\quad(c M)\end{array}$ & $\begin{array}{l}\text { Coupling/ } \\
\text { repulsion }\end{array}$ & $\begin{array}{l}\text { Linked markers }{ }^{h} \\
\quad \text { (no.) }\end{array}$ & $N$ & $P$ \\
\hline adp, awned palea & - & $a d p$ & BGS & Chr. $3 \mathrm{H} / 27$ & + & - & E3634-8 & 5.8 & $\mathrm{c}$ & 4 & 41 & \\
\hline als, absent lower laterals & - & als & BGS & Chr. $3 \mathrm{H} / 28$ & - & + & E4234-11 & 0.0 & c & 2 & & 50 \\
\hline aur-a1, auricleless a1 & aur & lig & UD & Chr. $2 \mathrm{H} / 20$ and 21 & + & - & E4034-3 & 4.1 & c & 5 & 39 & \\
\hline aur-a2, auricleless a2 & aur & lig & UD & Chr. $2 \mathrm{H} / 21$ & + & - & E3633-1 & 1.6 & $\mathrm{r}$ & 3 & 42 & \\
\hline br1, brachytic & - & brh1 & BGS & Chr. $1 \mathrm{H} / 1$ & + & + & E4134-8 & 5.0 & $\mathrm{c}$ & 5 & 15 & 24 \\
\hline br-2, brachytic dwarf & - & brh2 & BGS & Chr. $4 \mathrm{H} / 38-40$ & + & + & E4140-7 & 0.0 & c & 15 & 34 & 29 \\
\hline bra-d7, bracteatum d7 & $b r a$ & $\operatorname{trd}$ & UD & Chr. 1H/gap & + & - & E3634-7 & 4.1 & c & - & 40 & \\
\hline cul15, uniculm 15 & cul & cul4 & UD & Chr. $3 \mathrm{H} / 32$ & + & + & E4143-4 & 0.0 & c & 8 & 19 & 16 \\
\hline cul16, uniculm 16 & cul & cul4 & UD & Chr. $3 \mathrm{H} / 31$ and 32 & + & - & E4144-5 & 8.0 & c & 9 & 36 & \\
\hline cul3, uniculm 3 & cul & cul4 & UD & Chr. $3 \mathrm{H} / 31$ and 32 & + & - & E4038-1 & 5.5 & c & 5 & 20 & \\
\hline cul5, uniculm 5 & cul & cul4 & UD & Chr. $3 \mathrm{H} / 32$ and 33 & + & - & E4244-3 & 6.9 & c & 5 & 30 & \\
\hline den 6 , densinodosum 6 & den & mnd6 & UD & Chr. $5 \mathrm{H} / 65$ & - & + & E3743-3 & 0.0 & c & 4 & & 16 \\
\hline den8, densinodosum 8 & den & mnd6 & UD & Chr. $5 \mathrm{H} / 65$ & - & + & E3640-1 & 3.9 & c & 6 & & 28 \\
\hline dub-1, double seed 1 & - & $d u b-1$ & UD & Chr. $5 \mathrm{H} / 66$ and 67 & + & + & E4038-4 & 0.0 & c & 11 & 38 & 23 \\
\hline hex-v3, hexastichon v3 & $h e x-v$ & vrs1 & UD & Chr. 2H/19-21 & + & - & E4343-7 & 3.5 & $\mathrm{r}$ & 7 & 40 & \\
\hline hex-v4, hexastichon v4 & $h e x-v$ & vrs1 & UD & Chr. $2 \mathrm{H} / 19$ and 20 & + & - & E3438-3 & 10.8 & c & 5 & 27 & \\
\hline int c.5, intermedium c5 & int & int-c & UD & Chr. $4 \mathrm{H} / 8$ & + & + & E4143-5 & 3.5 & $\mathrm{r}$ & 9 & 31 & 30 \\
\hline K Hooded & $K$ & Kap & BGS & chr $4 \mathrm{H} / 36$ and 37 & + & - & E4140-1 & 5.1 & $\mathrm{c}$ & 3 & $72^{j}$ & \\
\hline li, liguleless & $\operatorname{lig}$ & lig & BGS & Chr. $2 \mathrm{H} / 22$ and 23 & + & + & E3544-9 & 6.8 & c & 5 & 35 & 19 \\
\hline lig-a2, liguleless a2 & lig & lig & UD & Chr. $2 \mathrm{H} / 21$ & + & - & E4244-8 & 5.0 & c & 6 & 29 & \\
\hline lk2, short awn & - & lks2 & BGS & Chr. $7 \mathrm{H} / 6$ & + & + & E4138-3 & 3.6 & c & 8 & 29 & 29 \\
\hline lk5, short awn & - & $l k s 5$ & BGS & Chr. $4 \mathrm{H} / 38$ & + & - & E4143-5 & 0.0 & c & 7 & 56 & \\
\hline sld1, slender dwarf 1 & - & sld1 & FIOR & Chr. $3 \mathrm{H} / 27$ & + & - & E3634-8 & 1.2 & c & 6 & 44 & \\
\hline sld4, slender dwarf 4 & - & sld4 & FIOR & Chr. $7 \mathrm{H} / 6$ & + & - & E4134-2 & 0.0 & c & 4 & 14 & \\
\hline tr, triple awned lemma & - & trp & BGS & Chr. $2 \mathrm{H} / 22$ and 23 & - & + & E3644-13 & 0.0 & c & 5 & & 30 \\
\hline trd, third outer glume & - & trd & BGS & Chr. $1 \mathrm{H} / 52$ & + & - & E3634-7 & 2.5 & c & 2 & 57 & \\
\hline uc2, uniculm 2 & - & cul2 & BGS & Chr. $6 \mathrm{H} / 54$ & + & - & E4343-10 & 9.2 & c & 5 & 31 & \\
\hline unc $c^{\mathrm{k}}$, uniculm & - & - & MPIZ & Chr. $6 \mathrm{H} / 54$ & + & - & E4034-2 & 10.0 & $\mathrm{c}$ & 4 & 37 & \\
\hline uz, semibrachytic & - & uzu & BGS & Chr. $3 \mathrm{H} / 27$ & + & - & E3733-6 & 10.1 & c & 5 & 24 & \\
\hline
\end{tabular}

aNomenclature as in Castiglioni et al (1998). The recommended nomenclature refers to Franckowiak and Lundqvist (2002). 'BGS, MPIZ, FIOR, UD: the abbreviations are explained in Materials and methods. 'Both linkage and linkage subgroups are reported. Chromosome number refers to syntenic linkage groups of Triticeae with $\mathrm{H}$ for Hordeum. Numbering formerly adopted for barley was Chromosome 1=7H; Chromosome 2=2H; Chromosome 3=3H; Chromosome $4=4 \mathrm{H}$; Chromosome $5=1 \mathrm{H}$; Chromosome $6=6 \mathrm{H}$; Chromosome $7=5 \mathrm{H}$. Species-Specific structural

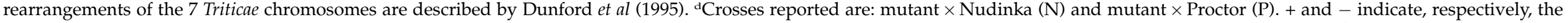

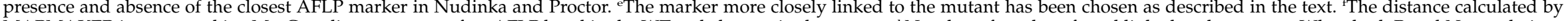

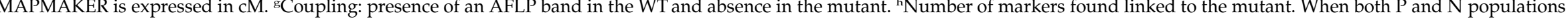
were considered, the number given includes markers from both crosses. A list of linked markers can be found at the www.diprove.unimi.it web site, Table 3 . iThe entry refers to the numbers of $\mathrm{F}_{2}$ recessive plants in the mapping populations. ${ }^{\mathrm{A}} \mathrm{A}$ total of 41 dominants $\mathrm{F}_{3}$ Hooded lines $(K K)$ and 31 recessive $(k k)$ lines. ${ }^{\mathrm{k}}$ Symbol assigned in this paper; see text. 
Table 2 Data concerning the Igri $\times$ Danilo molecular linkage map

\begin{tabular}{lccc}
\hline & Markers & $\begin{array}{c}\text { No. of preliminary } \\
\text { linkage groups }\end{array}$ & $\begin{array}{c}\text { Total length } \\
(\text { cM) }\end{array}$ \\
\hline Chromosome 1H & 21 & 2 & 116 \\
Chromosome 2H & 65 & 3 & 511 \\
Chromosome 3H & 26 & 2 & 295 \\
Chromosome 4H & 34 & 3 & 293 \\
Chromosome 5H & 69 & 2 & 586 \\
Chromosome 6H & 72 & 2 & 488 \\
Chromosome 7H & 81 & 3 & 620 \\
\hline
\end{tabular}

placed off-end by the ORDER command or that could not be positioned by three-point analysis or by the TRY routine. The reduction in the number of usable markers also applied to bridge bands (from 72 to 61), mainly because of discrepancies in their new map positions as compared with those derived from the Proctor $\times$ Nudinka map. This could be explained by the fact that while generating a large number of polymorphisms per gel, the AFLP procedure produces a small fraction of bands with similar mobilities in gels and which map to different linkage groups. The final robustness of the new map, as obtained here for the Igri $\times$ Danilo population, relies on the linkages of bridge bands with loci segregating only in the Igri $\times$ Danilo cross. Eventually, 16 bridge markers were allocated to Chromosome $7 \mathrm{H} ; 11$ to Chromosome $2 \mathrm{H}$; five to Chromosome $3 \mathrm{H}$; eight to Chromosome $4 \mathrm{H}$; six each to Chromosomes $1 \mathrm{H}$ and $6 \mathrm{H}$ and nine to Chromosome $5 \mathrm{H}$. The order of, and the relative distance between, bridge markers in the 17 chromosomal regions mapped in the cross Igri $\times$ Danilo were in agreement with the data of Castiglioni et al (1998).

Data concerning the number of AFLP markers mapped on the Igri $\times$ Danilo linkage groups, the number of preliminary linkage groups assigned to each chromosome and the map length are reported in Table 2. A significant map expansion in comparison to the previous RFLP-AFLP was observed, particularly in marker-dense regions (ie on Chromosomes $7 \mathrm{H}$ and $4 \mathrm{H}$ ). Grouping of markers in specific regions of the seven linkage groups described in Castiglioni et al (1998) identified, in that map, linkage subgroups. The same nomenclature was adopted to indicate linkage subgroups in the Igri $\times$ Danilo map, as described in the cited web site. A graphic representation and statistics of the Igri $\times$ Danilo linkage map are obtainable at the web site http:// www.diprove.unimi.it (PDF files and Table).

\section{Mapping of 29 barley developmental mutants}

A procedure that allows rapid mapping to barley linkage groups of mutant alleles of genetically characterized loci is described in Castiglioni et al (1998). The procedure uses homozygous recessive $\mathrm{F}_{2}$ plants segregating in crosses between the mutants and the two WT lines Proctor and Nudinka, the parents of the population used to create the reference AFLP map. This procedure was used to map the loci branched and calcaroides (Castiglioni et al, 1998; Pozzi et al, 2000) and it is extended in this paper to a group of developmental mutants. The mapping approach was iterative: once an AFLP poly- morphism revealed linkage to a genetic locus, other primer combinations were selected to generate AFLP fragments which, based on the Proctor $\times$ Nudinka and Igri $\times$ Danilo AFLP maps, were predicted to be in closer linkage to the mutant. The mapping data obtained are reported in Table 1. For each mutant, its map position in the linkage subgroups of Castiglioni et al (1998) or in an interval spanning linkage subgroups, or in regions poor in polymorphic markers (the latter situation applied to two cases, mutations bra-d7 and unc) is listed.

For most mutants, $F_{2}$ plants from the cross mutant $\times$ Nudinka proved to be sufficiently informative. In some cases, however, it was necessary to reinforce the map position by using $\mathrm{F}_{2}$ plants from the Proctor cross (Table 1). In the case of the mutant bra-d7, the linked AFLP marker could not be localized on the Proctor $\times$ Nudinka map, but the data available for the Igri $\times$ Danilo population made it possible to map it offend on Chromosome $1 \mathrm{H}$.

The AFLP marker in closest linkage with the mutant locus, as determined in coupling configuration on the largest mapping population analyzed, is indicated in Table 1 as the closest marker. The recombination distance between the closest marker and the next mutant locus ranged from 0 to $23 \mathrm{cM}$, with an average of $3.8 \mathrm{cM}$. In about one-fourth of cases, the iterative procedure was performed until no recombinants were found between marker and mutant. In Table 1, the number of markers within a linkage subgroup and linked to a given mutant is also reported. In few cases, only two markers were found linked to the mutant because of the absence of polymorphisms for other markers of the region. The number of individuals included in the mapping populations was kept low to allow a rapid screening by AFLP: mapping populations ranged in size from 16 to $72 F_{3}$ individuals (Table 1 ).

In some cases, our data provide molecular markers for mutants previously assigned to chromosomes by linkage to other classical markers, thus contributing linkage subgroups mapping. The mutants adp, bra-d7, cul3, cul5, cul15, cul16, den6, den8, dub-1, sld4 and unc were here assigned to precise positions in specific linkage groups for the first time.

The mutant awned palea ( $a d p$ ) was described by Ahokas (1977), and was mapped here for the first time to Chromosome $3 \mathrm{H}$, linkage subgroup 27 (Figure 1).

The absent lower laterals (als) locus (Kasha and Walker, 1960; Tsuchiya and Haus, 1971) is here precisely mapped on Chromosome 3H, linkage subgroups 28 and 29. For this locus, the revised nomenclature uses the same symbol. The mutant was induced with $\gamma$-rays in the variety Montcalm (Franckowiak, 1997).

The mutations auricleless (aur-a1 and aur-a2) and liguleless (lig-a2 and li), which affect ligule-auricle development, all mapped on Chromosome $2 \mathrm{H}$, in an interval spanning sublinkage groups $21-23$. The allele $l i$ (lig), obtained from BGS, a spontaneous mutant that is allelic to the Swedish aur mutants (Tsuchiya, 1973a), is confirmed to map to Chromosome $2 \mathrm{H}$ as reported by Takahashi et al (1953). The mapping data confirm allelism tests conducted by U Lundqvist (personal communication) in that aur-a1 and aur-a2 are allelic and both map on Chromosome $2 \mathrm{H}$, linkage subgroups 20 and 21. The liga2 mutant is not allelic to $l i$, according to U Lundqvist (personal communication), but both mutants comap with 


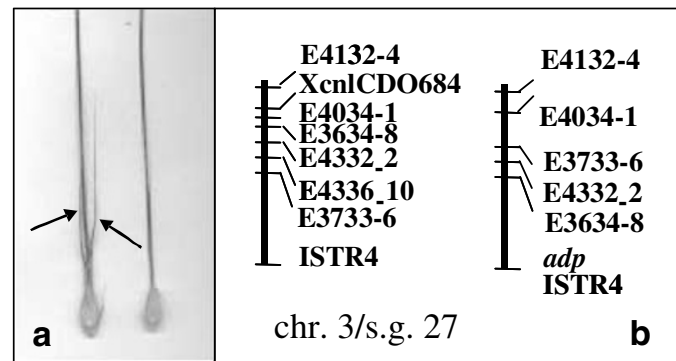

Figure 1 Mapping of awned palea (adp), one of the 29 recessive Mendelian loci integrated into the molecular marker map described here. (a) Mutant (left) and WT (right) florets of barley. The mutant is characterized by the presence of an awn not only on the lemma but also on the palea (indicated by the arrows). Because the palea ontogenetically derives from the fusion of two bracts (Williams, 1975), there are actually two awns on this organ. (b) Map position of the mutation $a d p$ on Chromosome $3 \mathrm{H}$, linkage subgroup 27 of the Proctor $\times$ Nudinka map. Left: Proctor $\times$ Nudinka map. Right: mapping in the cross $a d p \times$ Nudinka.

aur mutations. The recommended nomenclature proposes also for lig-a2 the symbol lig.

Two brachytic mutants $b r$ and $b r 2$ (Franckowiak, 1995) were previously studied: br1 maps on Chromosome 7H, and is now assigned to sublinkage group 1 of the same Chromosome. The mutant arose spontaneously in the variety Himalaya. The second mutant, br2, maps between sublinkage groups 38 and 40 on Chromosome $4 \mathrm{H}$, confirming the chromosomal assignment given by Tsuchiya (1980). br2 was induced by X-ray treatment in the variety Svanhals (Tsuchiya, 1962). The recommended nomenclature for these mutants is $b r h$. The semibrachytic mutant $u z$, obtained from BGS, is a spontaneous mutation present in several Japanese varieties. The mutant was previously assigned to Chromosome $3 \mathrm{H}$ (Takahashi and Yamamoto, 1951; Tsuchiya, 1980). We mapped this mutant to sublinkage group 27 of Chromosome $3 \mathrm{H}$. The symbol for the mutant locus in the recommended nomenclature is $u z u$.

The third outer glume (trd) mutants, also referred to as bracteatum (bra; Gustafsson et al, 1969), have been frequently investigated. The bract-like structures that in the mutant cover a triplet of spikelets, are homologous to a normal leaf. Our data support the possibility that bra- $d 7$ (which maps on Chromosome $1 \mathrm{H}$ south of sublinkage group 52), a mutant obtained from the Svalöf collection, and trd (which maps in the same chromosomal region and was obtained from the BGS) could be allelic. Tsuchiya (1974) previously proposed that bra-c1 and trd were alleles. The mapping data support the assignment by Konzak (1953) and Søgaard and von WettsteinKnowles (1987) to Chromosome 1H. bra-d7 was obtained from Dr U Lundqvist (Svalöf collection) and trd is the symbol used in the recommended nomenclature.

The uniculm mutants (uc in Søgaard and von WettsteinKnowles, 1987) are characterized by a single culm and the absence of lateral tillers. The mutants we have considered include a group obtained from Svalöf induced with X-rays and represented by cul3, cul5, cul15 and cul16, which all map on Chromosome $3 \mathrm{H}$, sublinkage groups 31-33. The second group includes the mutant $u c 2$ obtained from BGS (Shands, 1963) and unc isolated at MPIZ. Both mutants map on Chromosome $6 \mathrm{H}$ close to sublinkage group 54 in a region already identified for $u c 2$ by Robertson et al (1965). In the recommended nomenclature the two different loci hosting uniculm mutants are designated cul2 and cul4 (Table 1).

The two densinodosum mutants den6 and den 8 originated from the Svalöf collection, but allelism tests were not available. Similar mutations (multinoded branched, $m n b$ ) were described by Walker et al (1963) and (multinoded dwarf, mnd) by Prasad and Tripathi (1985), following the first description by Gustafsson (1947). Both den 6 and den 8 are now mapped on Chromosome 5H, sublinkage group 65 . The recommended nomenclature uses the symbol mnd6 for this locus.

The mutant double seed 1 (dub-1) was obtained from the Svalöf collection and is here mapped to Chromosome $5 \mathrm{H}$, linkage subgroups 66 and 67.

The two six-row ear character is controlled in barley by several independent gene loci, including the $v$ locus on Chromosome 2H (Nilan, 1964) - with the six-rowed allele $v$ being inherited recessively - and the allelic series for the fertility of the lateral florets on Chromosome $4 \mathrm{H}$ (Gymer, 1977). A group of intermedium genes has been described that control the same character (Lundqvist, 1981; Lundqvist and Lundqvist, 1998): the int-c5 locus is assigned to Chromosome 4H (Woodward, 1949; Gymer, 1977). Based on our data, this locus maps to the same chromosome, linkage subgroup 38. Most of the induced recessive mutants at the $v$ locus are designated by the symbol hex-v (Gustafsson et al, 1969; Søgaard and von Wettstein-Knowles, 1987). We have mapped two such alleles obtained from the Svalöf collection, hex-v3 and hex- $v 4$, and they are, as expected, located on Chromosome $2 \mathrm{H}$, linkage subgroups 19,20 . This locus is now indicated by the symbol vrs1.

Hooded $(K)$ is a dominant mutant introduced into western countries from the Himalayas (Harlan, 1931; Stebbins and Yagil, 1966; Badr et al, 2000). The mutation is caused by a tandem direct duplication on 305bp in the fourth intron of homeobox gene $B k n 3$, resulting in the ectopic overexpression of BKN3 at the lemma-awn transition region: a local acquisition of meristematic activity is followed by the formation on the lemma of extra floral structures (Müller et al, 1995). The locus was assigned to Chromosome $4 \mathrm{H}$ and now it has been associated to linkage subgroup 37 of the same linkage group. The recommended symbol is Kap.

The short awn (lk) mutants constitute a family of loci that map to different chromosomes (Tsuchiya, 1973b). lk5 (Litzenberger and Green, 1951) was confirmed in this work to map on Chromosome 4H (Tsuchiya, 1980) linkage subgroup 38, while $l k 2$ (Takahashi et al, 1953) lies on Chromosome $7 \mathrm{H}$, linkage subgroup 6. The two loci now have the recommended symbols $l k s 5$ and $l k s 2$, respectively. The mutant slender dwarf (sld1) was induced by EMS treatment (Konishi, 1975; Szarejko and Maluszinski, 1984) and the gene was localized on Chromosome $3 \mathrm{H}$ near the mutant locus uzu (Konishi et al, 1984). We have now refined this map position by assigning the locus to linkage subgroup 27. The symbol for sld1 remains unchanged in the recommended nomenclature. sld4 obtained from FIOR was mapped here, for the first time, to Chromosome $7 \mathrm{H}$, linkage subgroup 6.

The mutant triple awned lemma (tr; Martini and Harlan, 1942) was here mapped to Chromosome $2 \mathrm{H}$, linkage 
subgroups 22-23, in accordance with Immer and Henderson (1943). The recommended symbol for the mutant is trp.

The mapping activity reported is based on the use of AFLP markers, which allow one to score several polymorphic loci in a single gel lane (Zabeau and Vos, 1993). When the goal is the construction of a molecular map of general value in genetic or plant breeding studies, the assumption has to be made that cosegregating AFLP bands produced by amplifying DNAs of different genotypes derive from identical DNA sequences. This seems to be the case for barley (Waugh et al, 1997). Qi et al (1998) and Qi and Lindhout (1996), for example, have produced an integrated AFLP map of barley linkage groups starting from four different segregating populations, using bridge AFLP bands common to the populations considered and migrating at the same positions in AFLP gels. A recent study based on AFLP band sequencing indicates that, even in interspecific comparisons within the genus Hordeum, AFLP product size and band intensity are reliable indicators of band DNA homology (El Rabey et al, 2002). It is therefore envisionable that AFLP polymorphisms mapped in one population serve as chromosomespecific markers, if they also segregate in a second one. Some exceptions to this generalization have, however, been noted: in this paper, the map positions of bridge markers agreed in general with published maps. Discrepancies noted could be due to coincidental comigration of AFLP fragments derived from distinct genomic positions. Duplications of parts of the genome, as well as the existence in barley of a large genome fraction made up of repetitive sequences (Barakan et al, 1997), can account for the phenomenon. This complication, in any case, did not interfere with the incorporation into the Proctor $\times$ Nudinka map of AFLP loci from the Igri $\times$ Danilo cross. Although the two populations have no parents in common, and even if the parental lines themselves are not closely related, 61 common AFLP markers (17\% of the total mapped) were available for the alignment of the two maps. The linkage map obtained was in good agreement with previously published maps (Becker et al, 1995; Castiglioni et al, 1998; Qi et al, 1998 and references therein). This successful integration makes now available a total of 819 AFLP marker loci useful for future mutant mapping and cloning in barley.

The major contribution of this paper is the mapping data for 29 Mendelian mutants. This allows to integrate these loci into a molecular map with an average density of about one AFLP marker every $3 \mathrm{cM}$. The average distance between the mapped genetic loci and the nearest AFLP marker is $3.8 \mathrm{cM}$, but frequently no recombination events were detected. The small number of $\mathrm{F}_{2}$ plants analyzed may have contributed to reduce the probability of finding recombinants, but local maker density frequently made also possible to select markers comapping with mutants.

\section{Acknowledgements}

This work was funded by the EGRAM-EuDicotMap Project of the European Community.

\section{References}

Ahokas H (1977). A mutant of barley: awned palea. Barley Genetics Newsletter 7: 8-10.

Badr A, Müller K, Schaefer-Pregl R, El Rabey H, Effgen S, Ibrahim $\mathrm{HH}$ et al (2000). On the origin and domestication history of barley (Hordeum vulgare). Mol Biol Evol 17: 499-510.

Barakan A, Carels N, Bernardi G (1997). The distribution of genes in the genomes of Gramineae. Proc Natl Acad Sci USA 94: 6857-6861.

Becker J, Vos P, Kuiper M, Salamini F, Heun M (1995). Combined mapping of AFLP and RFLP markers in barley. Mol Gen Genet 249: 65-73.

Bossinger G, Lundqvist U, Rohde W, Salamini F (1992). Genetics of plant development in barley. In: Munck L (ed) Barley Genetics VI, Munksgaard Intl. Publ. Ltd: Copenhagen, Denmark. pp 989-1022.

Büschges R, Hollricher K, Panstruga R, Guus S, Wolter M, Frijters A et al (1997). The barley Mlo gene: a novel control element of plant pathogen resistance. Cell 88: 695-705.

Byrne PF, McMullen MD, Snook MD, Musket TA, Thuri JM, Widstrom NW et al (1996). QTLs and metabolic pathways genetic control of the concentration of maysin, a corn earworm resistance factor, in maze silks. Proc Natl Acad Sci USA 93: 8820-8825.

Castiglioni P, Pozzi C, Heun M, Terzi V, Müller KJ, Rohde W et al (1998). An AFLP-based procedure for the efficient mapping of mutations and DNA probes in barley. Genetics 149: 20392056.

Dunford RP, Kurata N, Laurie DA, Money TA, Minobe Y, Moore $G$ (1995). Conservation of fine-scale DNA marker order in the genomes of rice and the Triticeae. Nucleic Acids Res 23: 27242728 .

El Rabey HA, Badr A, Schäfer-Pregl R, Martin B, Salamini F (2002). Species separation and incipient speciation in Hordeum (Poaceae) resolved by discontinuous molecular markers. Plant Biol 4: 1-9.

Faris JD, Li WL, Liu DJ, Chen PD, Gill BS (1999). Candidate gene analysis of quantitative disease resistance in wheat. Theor Appl Genet 98: 219-225.

Franckowiak J (1995). The brachytic class of semidwarf mutants in barley. Barley Genetics Newsletter 24: 56.

Franckowiak J (1997). Revised linkage maps for morphological markers in barley, Hordeum vulgare. Barley Genetics Newsletter 26: 9-21.

Franckowiak J, Lundqvist U, Konishi T (1997). New revised names for barley genes. Barley Genetics Newsletter 26: 4.

Franckowiak JD, Lundqvist U (2002). Descriptions of barley genetic stocks for 2001. Barley Genetics Newsletter 32: 49-137.

Gustafsson A (1947). Mutations in agricultural plants. Hereditas 33: $1-100$

Gustafsson A, Hagberg A, Lundqvist U, Persson G (1969). A proposed system of symbols for the collection of barley mutants at Svalof. Hereditas 62: 409-414.

Gymer PT (1977). Probable allelism of $I i$ and Int-c genes. Barley Genetics Newsletter 7: 34-35.

Harlan HV (1931). The origin of Hooded barley. J Hered 22: 265272.

Heun M, Kennedy E, Anderson JA, Lapitan NLV, Sorrels ME, Tanksley SD et al (1991). Construction of a restriction fragment length polymorphism map for barley (Hordeum vulgare). Genome 34: 437-447.

Immer FR, Henderson MT (1943). Linkage studies in barley. Genetics 28: 419-440.

Kasha KJ, Walker GWR (1960). Several recent barley mutants and their linkages. Can J Genet Cytol 2: 397-415.

Konishi T (1975). Characteristics and inheritance of EMSinduced mutants in barley. Nogaku Kenkyu 55: 53-56.

Konishi T, Hayashi J, Moriya I, Takahashi R (1984). Inheritance and linkage studies in barley VII. Location of six new genes 
on chromosome 3. Ber Ohara Ins Landwirstch Forsch 18: 251264.

Konzak CF (1953). The third outer glume character in barley. J Hered 44: 39-40.

Lander ES, Green P, Abrahamson J, Barlow A, Daly MJ, Lincoln SE et al (1987) MAPMAKER: an interactive computer package for constructing primary genetic linkage maps of experimental and natural populations. Genomics 1: 174-181.

Lahaye T, Hartmann S, Topsch S, Freialdenhoven A, Yano M, Schulze-Lefert P (1998). High-resolution genetic and physical mapping of the Rar1 locus in barley. Theor Appl Genet 97: 526534.

Litzenberger SC, Green JM (1951). Inheritance of awns in barley. Agron J 43: 117-123.

Lukowitz W, Gillmor CS, Scheible W-R (2000). Positional cloning in Arabidopsis. Why it feels good to have a genomic initiative working for you. Plant Physiol 123: 795-805.

Lundqvist U (1981). Intermedium and hexastichon mutants in barley. Barley Genetics IV - Proceedings of the IV International Barley Genetics Symposium, pp 908-912.

Lundqvist U, Lundqvist A (1998). Induced intermedium mutants in barley: origin, morphology and inheritance. Hereditas 108: 13-26.

Lundqvist U, Franckowiak JD, Konishi T (1997). New and revised description of barley genes. Barley Genetics Newsletter 26: 22 .

Martini ML, Harlan HV (1942). Barley Freaks. J Hered 33: 338343.

Molinero-Rosales N, Jamilena M, Zurita S, Gomez P, Capel J, Lozano R (1999). FALSIFLORA, the tomato orthologue of FLORICAULA and LEAFY, controls flowering time and floral meristem identity. Plant J 20: 685-693.

Müller KJ, Romano N, Gerstner O, Garcia-Maroto F, Pozzi C, Rohde W et al (1995). The barley Hooded mutation caused by a duplication in a homeobox gene intron. Nature 374: 727-730.

Müller J, Wang Y, Franzen R, Santi L, Salamini F, Rohde W. (2001). In vitro interactions between barley TALE homeodomain proteins suggest a role for protein-protein associations in the regulation of Knox gene function. Plant J 27: 1323.

Nilan RA (1964). The cytology and genetics of barley 1951-1962. In: Monographic Supplement, No. 3, Washington State University Press: Washington, DC. Vol 32, pp 1-278.

Pozzi C, Faccioli P, Terzi V, Stanca AM, Cerioli S, Castiglioni P et al (2000). Genetics of mutation affecting the development of a barley floral bract. Genetics 154: 1335-1346.

Prasad G, Tripathi DK (1985). Induced multinoded mutants in barley. Barley Genetics Newsletter 15: 10-12.

Qi X, Lindhout P (1996). Comparison and integration of four barley genetic maps. Genome 39: 379-394.

Qi X, Stam P, Lindhout P (1998). Use of locus-specific AFLP markers to construct a high-density molecular map in barley. Theor Appl Genet 96: 376-384.

Richmond T, Somerville S (2000). Chasing the dream: plant EST microarrays. Curr Opin Plant Biol 3: 108-116.
Robertson DW, Wiebe GA, Shands RG, Hagberg A (1965). A summary of linkage studies in cultivated barley, Hordeum species: Supplement III, 1954-1963. Crop Sci 5: 33-43.

Schmitz J, Franzen R, Nguyen TH, Garcia-Maroto F, Pozzi C, Salamini $F$ et al (2000). Cloning, mapping and expression analysis of barley MADS-box genes. Plant Mol Biol 42: 899913.

Schwarz G, Michalek W, Mohler V, Wenzel G, Jahoor A (1999). Chromosome landing at the Mla locus in barley (Hordeum vulgare L.) by means of high-resolution mapping with AFLP markers. Theor Appl Genet 98: 521-530.

Shands RG (1963). Inheritance and linkage of orange lemma and uniculm characters. Barley Genetics Newsletter 6: 35-36.

Søgaard B, von Wettstein-Knowles P (1987). Barley: genes and chromosomes. Carlsberg Res Commun 52: 123-196.

Stebbins GL, Yagil E. (1966). The morphogenetic effects of the Hooded gene in barley. I. The course of development in Hooded and Awned genotypes. Genetics 54: 727-741.

Szarejko I, Maluszinski M (1984). Two new dwarfism genes on barley chromosome 3. Barley Genetics Newsletter 14: 35-38.

Takahashi R, Yamamoto J (1951). Studies on the classification and geographical distribution of Japanese barley varieties. III. On the linkage relation and the origin of the $u z u$ or semibrachytic character in barley. Ber Ohara Inst Landwirtsch Biol, Okayama Univ 9: 399-410.

Takahashi R, Yamamoto J, Yasuda S, Itano Y (1953). Inheritance and linkage studies in barley. Ber Ohara Inst Landwirtsch Biol, Okayama Univ 10: 29-52.

Tsuchiya T (1962). Radiation breeding in two-rowed barley. Seiken Jiho 14: 21-34.

Tsuchiya T (1973a). Allelism testing between established marker stocks and Swedish mutants. Barley Genetics Newsletter 3: 67.

Tsuchiya T (1973b). New linkage maps of barley. Barley Genetics Newsletter 3: 99-103.

Tsuchiya T (1974). Further results of allelism testing in barley. Barley Genetics Newsletter 4: 82-85.

Tsuchiya T (1980). Description of genetics stocks. Barley Genetics Newsletter 10: 108-119.

Tsuchiya T, Haus TE (1971). Absent lower laterals. Barley Genetics Newsletter 1: 123.

Walker GW, Dietrich J, Miller R, Kasha K (1963). Recent barley mutants and their linkages. II. Genetic data for further mutants. Can J Genet Cytol 5: 200-219.

Waugh R, Bonar N, Baird E, Thomas B, Graner A, Hayes P et al (1997). Homology of AFLP products in three mapping populations of barley. Mol Gen Genet 255: 311-321.

Williams RF (1975). The Shoot Apex and Leaf Growth, Cambridge University Press: Cambridge.

Woodward RW (1949). The inheritance of fertility in the lateral florets of the four barley groups. Agron J 41: 317-322.

Zabeau M, Vos P (1993). Selective restriction fragment amplification: a general method for DNA fingerprinting. European Patent Application no. 92402629.7. 